\title{
Influence of country of birth and ethnicity on body mass index among Canadian youth: a national survey
}

\author{
Atif Kukaswadia MSc, William Pickett PhD, Ian Janssen PhD
}

Abstract

Background: The body mass index (BMI) of youth often changes when they immigrate to a new country as a result of the adoption of new behaviours, a process called acculturation. We investigated whether BMI differs by country of birth (Canada v. other countries) and ethnicity, both individually and together. We also examined whether time since immigration and health-related behaviour explain any observed BMI differences.

Methods: Data sources were the Canadian Health Behaviour in School-Aged Children study and the Canada Census of Population. Participants were youth in grades $6-10$ (weighted sample $n=19272$ ). A questionnaire was used to assess participants' sociodemographic characteristics, height, weight and health-related behaviour. We calculated BMls from participants' self-reported heights and weights and used World Health Organization growth references to determine BMI percentiles.

Results: Based on self-reported heights and weights, BMI percentiles for foreign-born youth were lower than those of youth born in Canada $(-4,95 \%$ confidence interval $[\mathrm{Cl}]-6$ to -2$)$. This difference did not decrease with time since immigration. Similarly, BMI percentiles were lower among East and Southeast Asian youth than their peers from the Canadian host culture $(-4,95 \% \mathrm{Cl}-6$ to -2$)$. Finally, BMI percentiles for foreign-born Arab and West Asian youth and East Indian and South Asian youth were lower than their Canadian-born peers of the same ethnicity $(-14,95 \% \mathrm{Cl}-22$ to $-7 ;-8,95 \% \mathrm{Cl}-14$ to -3$)$.

Interpretation: Immigrant generation and ethnicity were related to BMI among Canadian youth, both independently and together. Some ethnic groups showed differences by country of birth, i.e., East Indian and South Asian, while others showed no such difference, i.e., East and Southeast Asian. There was no association with time since immigration. Our findings reinforce the need to investigate country of birth and ethnicity when considering the determinants of childhood BMI.

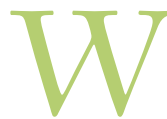
hen a person immigrates to a new country, his or her health changes, eventually approximating that of people born in the host country, via a process called acculturation. ${ }^{1}$ One characteristic that could be influenced by acculturative changes in diet and physical activity is body mass index (BMI)..$^{2-5}$ This is an important factor because of the high prevalence of obesity and related health problems..$^{6-9}$ In Canada, immigrants have a lower BMI than their Canadian-born peers ${ }^{10,11}$; however, findings from international studies have been inconsistent. ${ }^{12-19}$

Two explanations have been proposed for these discrepancies. The "time since immigration" hypothesis suggests that people who have immigrated more recently are less acculturated than established immigrants who have had time to adopt the norms and behaviours of the host country ${ }^{17,20}$; this would lead to discrepancies among studies that did not take this factor into account. The second explanation is that BMI is driven by ethnic differences. Ethnicity is a determinant of BMI, with increased risks for overweight and obesity observed among Hispanic and black people, ${ }^{1,21}$ and lower risks among those of East and Southeast Asian descent. ${ }^{10-14}$ Thus, it is difficult to establish the etiologic pathway between birth status and BMI from existing studies, because they have not considered time since immigration, have focused on specific ethnic groups and have not explored interactions between immigration and ethnicity.

In this study of a national sample of Canadian schoolaged youth, we examined the independent and joint effects of country of birth and ethnicity on BMI. In subsequent analyses, we investigated the effect of time since immigration and whether differences in BMI persist after controlling for behaviours associated with obesity. We hypothesized that foreign-born youth would have a lower BMI than their Canadian-born peers, that this difference would diminish over time and that differences in BMI by ethnicity would exist.

Competing interests: See end of article.

This article has been peer reviewed.

Correspondence to: Atif Kukaswadia, atif.kukaswadia@queensu.ca CMAJ Open 2014.DOI:10.9778/cmajo.20130088 


\section{Methods}

\section{Data sources}

Data on young people were obtained from cycle 6 (2010) of the Canadian Health Behaviour in School-Aged Children (HBSC) study. Conducted under the auspices of the World Health Organization, HBSC is a self-reported general health survey completed by students in classrooms. ${ }^{22}$ The 2010 Canadian survey collected information from 26078 youth in grades 6-10 in 436 schools in 8 provinces and 3 territories (New Brunswick and Prince Edward Island did not participate). ${ }^{22}$ In each province, a systematic, multistage cluster sample approach was used, with whole classes selected from a list of eligible and consenting schools. In the 3 territories, a census of all students in grades 6-10 was attempted. Weighting was applied to ensure generalizability of estimates nationally.

Consent was obtained from school boards, schools, parents and children. Approximately 57\% of the schools approached agreed to participate, and $77 \%$ of the estimated number of students in schools that gave consent participated in the study. Less than $10 \%$ declined to participate or spoiled their questionnaires intentionally; the remaining nonparticipants generally failed to return consent forms, failed to receive parental consent or were absent on the day of the survey. ${ }^{22}$

\section{Sample population}

From the original sample of 26082 youth, 7299 were excluded because of missing data (Figure 1). This left a final, unweighted sample of 18 783, which was weighted according to the Canadian HBSC study protocol ${ }^{22}$ for a final sample of 19272. Included participants were slightly older than those who were excluded (14.0 yr v. $13.4 \mathrm{yr}, p<0.0001)$. More second- than firstgeneration youth provided all relevant covariable information (76\% v. $66 \%, p<0.0001)$ and response rates by ethnicity ranged from $64 \%$ to $76 \%$ (data not shown). No other differences were found between those included and excluded from the analyses.

Area-level population demographics were obtained from the 2006 Canada Census of Population. ${ }^{23}$ Census responses were linked to schools to describe the neighbourhoods in a 1-km radius around each school, a distance that has been previously shown to represent social constructs accurately. ${ }^{24}$

\section{Country of birth and ethnicity}

The study population was categorized by country of birth. This was determined through the HBSC survey question, "In which country were you born?" Youth born outside Canada were categorized as "foreign born," while youth born in Canada were classified as "Canadian born."

Second, youth were categorized into 5 groups by the length of time they had been in Canada based on the HBSC survey question, "How many years have you lived in Canada?" Response options were: "I was born in Canada," "1 to 2 years," "3 to 5 years" " 6 to 10 years" and " 11 or more years." Because of the small numbers in the fifth group, the last 2 groups were combined to form a " $\geq 6$ years" group.

Finally, youth were categorized into 7 ethnic groups based on the HBSC survey question, "How do you describe yourself?" and the 16 possible response options; youth were able to select up to 3 response categories. Responses were used to create the following ethnic groups: Canadian host culture, Arab and West Asian, African, East Indian and South Asian, East and Southeast Asian, Latin American and Other. These groups were based on the ethnic groupings defined by the 2006 Canadian Census of Population, with 3 modifications. ${ }^{23}$ First, European, North American and Aboriginal youth were combined to create the "Canadian host culture" group (ethics restrictions prohibited a separate study of Aboriginal youth). ${ }^{25}$ Second, West Asian and South Asian youth were combined because of the small numbers of the former. Finally, an additional group (Other) was created for youth who identified with more than 1 of the 6 identified ethnic groups.

\section{BMI percentile}

Youth self-reported their weight and height in metric or imperial units, as in previously validated instances. ${ }^{26}$ From these, BMI was calculated $\left(\mathrm{kg} / \mathrm{m}^{2}\right)$. To account for growth and maturation, participants' BMI values were converted to age- and sex-specific BMI percentile scores using World Health Organization growth references. ${ }^{27}$ These criteria define overweight and obese as +1 and +2 standard deviations, respectively. ${ }^{27}$

\section{Covariables}

Individual-level covariables collected via the HBSC survey were age, sex and perceived family wealth (self-perceived socioeconomic status), which are known predictors of BMI among youth. ${ }^{14,28-32}$ At the school level, covariables included population centre category,,$^{33}$ percentage of immigrants in the community and median income quartile.

Seven behaviours were considered as explanatory variables for observed differences in BMI percentile: time spent watching television; using a computer; playing video games; engaging in physical activity; snacking while watching television; snacking while on the computer or playing video games; and frequency of eating at fast-food restaurants. These were chosen as modifiable behaviours associated with BMI that may differ by ethnicity and country of birth. ${ }^{34,35}$ The first 3 behaviours were determined by asking the number of hours spent each day on that activity. ${ }^{36}$ Physical activity referred to the number of days a week on which the youth engaged in at least 60 minutes of moderate-tovigorous physical activity. ${ }^{37}$ Snacking was assessed by asking, "How often do you eat a snack while you watch TV (including videos and DVDs)?" with response options ranging from "never" to "every day." 38 A similar question asked about snacking while playing video games. Finally, 1 item was used to assess frequency of eating at fast food restaurants, with 7 possible responses ranging from "Never," and "Rarely (less than once a month)," to "5 or more days a week." 39

\section{Analysis}

For all analyses, we used a multilevel approach because of the clustered nature of the data and the inclusion of both individual- and school-level covariables. Level 1 refers to individuallevel and level 2 refers to school-level variables. ${ }^{40} \mathrm{We}$ used cross-tabulations to explore youth BMI percentile by each of 
the exposure variables. For all $p$ values calculated for associated statistical tests, we used the Rao-Scott $\chi^{2}$ test to control for clustering at the school level.

Multilevel linear regression was used to explore the relation between country of birth and BMI percentile. Country of birth and ethnicity were included in the modelling process, but time since immigration was not, as it is collinear with country of birth. Six hierarchical regression models were built with the outcome of BMI percentile, following established precedents. ${ }^{40}$ First, an empty model was built to investigate the random effect of school on BMI percentile. ${ }^{40}$ Second, a "base model" was created that included country of birth and ethnicity as predictors of BMI percentile. The third and fourth models controlled for individual- and school-level covariables, respectively. The fifth model included all covariables found to be significant in models 3 and 4, using a liberal value of $p<0.20$ to indicate significance. Finally, a sixth model was built that controlled for the variables identified for the adjusted model and investigated the effect of the 7 behaviours on potential differences in BMI percentile by country of birth and ethnicity.

We also investigated the interaction between country of birth and ethnicity by stratifying each ethnic group into 2 groups,
Canadian-born and foreign-born, while controlling for covariables identified in the sixth model.

All analyses were conducted using SAS v. 9.3 (SAS Institute, Cary, N.C., USA) using PROC SURVEYFREQ for crossitabulations and PROC MIXED for regression models. All analyses considered the sample weights and accounted for clustering at the school level.

\section{Ethics approval}

This study received ethics approval from the Queen's University General Research Ethics Board (GEDUC-430-09) and Health Sciences Research Ethics Board (6007743).

\section{Results}

Our sample was composed predominantly of youth born in Canada (91.6\%). Most self-identified as being part of the Canadian host culture (78.2\%). Other major ethnic groups included East and Southeast Asian (5.7\%), African (3.8\%) and East Indian and South Asian (2.9\%) (Table 1). Intraclass correlation analysis showed that school grade accounted for $2.7 \%$ of the variation in $\mathrm{BMI}$ percentile.

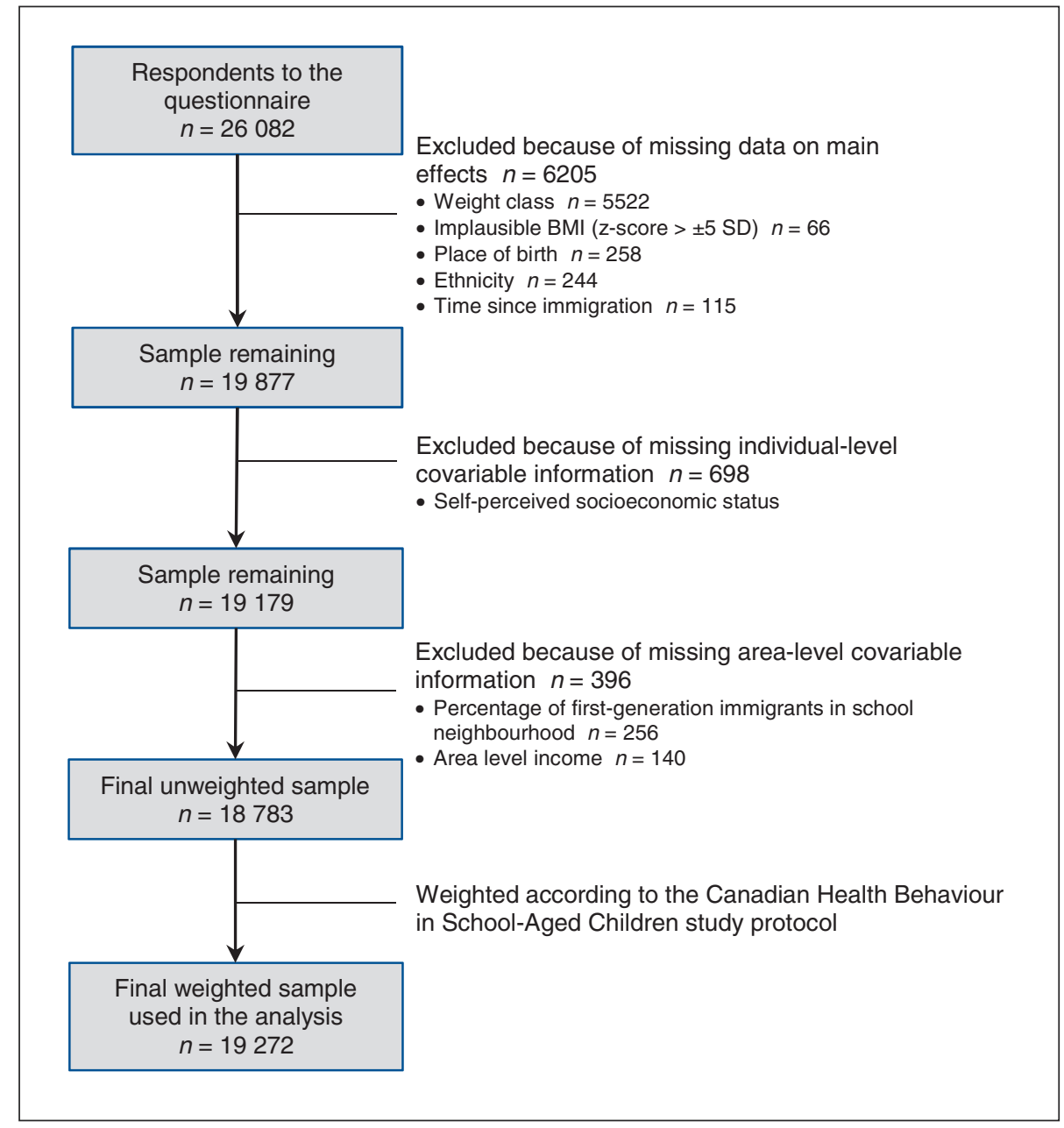

Figure 1: Process for selecting study population from respondents to the Canadian Health Behaviour in School-Aged Children, cycle 6 (2010) study. 
Differences in BMI percentile were observed by country of birth. The BMI of foreign-born youth was 4 percentile points lower $(95 \%$ confidence interval $[\mathrm{CI}]-6$ to -2$)$ than that of Canadian-born youth. Stratification of the foreign-born group showed that changes in BMI percentile were not linearly related to time since immigration, and only youth who had immigrated 6 or more years earlier were significantly different from those born in Canada (Table 1). The observed differences in BMI between countries of birth changed less than $6 \%$ after controlling for the 7 behaviours that we hypothesized may explain this relation (time spent watching television; using a computer; playing video games; engaging in physical activity; snacking while watching television; snacking while on the computer or playing video games; and frequency of eating at fast-food restaurants).

BMI differed by ethnicity. After adjusting for relevant covariables, the BMI of both the East Indian and South Asian group and the East and Southeast Asian group was 3-4 percentile points lower than that of the Canadian host culture group (Table 2). Minimal changes in effect estimates $(<3 \%)$ were observed for the ethnicity-BMI relation after controlling for the 7 behavioural factors.

The interaction between country of birth and ethnicity was statistically significant $(p=0.0002)$. Compared with Canadianborn youth of the same ethnicity, foreign-born Canadian host culture, Arab and West Asian youth and East Indian and South Asian youth had a lower BMI, with differences ranging from -6 to -14 percentile points (Table 3 ).

\section{Interpretation}

The most important finding of this study was that the BMI of foreign-born youth was lower than that of their Canadianborn peers, and that this association was not linear with time since immigration. This goes against the theory of acculturation. BMI also differed by ethnicity, with East and Southeast Asian youth having a lower BMI than youth of the Canadian host culture, irrespective of country of birth. These findings were robust and persisted after controlling for key behaviours associated with BMI. Finally, the relation between country of birth and BMI appeared to be modified by ethnicity.

Previous research that has examined the association between immigration status and obesity measures among youth has produced mixed findings. Studies of youth in Sweden and the United States both found that youth born abroad were more likely to be overweight and obese compared with their native-born peers. ${ }^{29,41}$ In Canada, boys who spent their entire life in Canada had 1.6-fold increased odds of being overweight (95\% CI 1.2-2.3). ${ }^{12}$ However, another Canadian study found no difference by country of birth. ${ }^{10}$ This is likely a result of demographic differences in the samples being investigated.

We were surprised to find that BMI did not change linearly with increased time since immigration. As in previous research of adults in Canada ${ }^{42}$ and the United States, ${ }^{3}$ we anticipated that differences in BMI would disappear over time. However, this was not the case, and we observed the opposite relation in our sample. This counters the theory of acculturation and may be explained by methodological issues, such as inadequate measurement or uncontrolled confounding. Age at immigration could not be controlled for because of the wide response categories, and this has been shown to be associated with BMI. ${ }^{3}$ In addition, family factors, such as parental country of birth, were not accounted for in this survey. Family-level factors, such as family practices, habits and beliefs, are key predictors of the health of youth during this developmental stage and could have an impact on childhood BMI. Finally, our measure of acculturation may not have been precise enough to show a relation. The lack of a linear relation between BMI and time since immigration remains a provocative and interesting finding and, in light of our conclusions, should be examined by ethnic group to ascertain the reason for this relation.

Compared with Canadian youth, we found that East and Southeast Asian youth reported heights and weights consistent with lower BMI irrespective of country of birth, a finding supported by others. ${ }^{10-13}$ Immigrant and ethnic differences in other determinants of obesity, such as insufficient sleep and smoking ${ }^{43}$ may explain these relations. We examined ethnicity and country of birth together to determine the effect of their possible interaction and found that foreign-born Canadian host culture, Arab and West Asian, and East Indian and South Asian youth had lower BMIs compared with Canadian-born youth of the same ethnicity. This may be because of an unhealthier diet pattern among the latter compared with foreign-born peers, as previously shown among Asian and Hispanic youth living in the United States. ${ }^{44}$ It is interesting that we observed no such relation among Asian and Latin American ethnic groups. An interaction between country of birth and ethnicity has been shown in studies of children and adolescents in the US and, as in our study, Asian ethnicity was associated with lower BMI. ${ }^{13}$ Second- and third-generation black youth, i.e., youth born in the US, but with parents or grandparents born abroad, were more likely to be overweight or obese. These differences may be attributable to different sociodemographic factors at play in the US and Canada. ${ }^{13}$

\section{Limitations}

We did not measure acculturation directly, but used country of birth and time since immigration as proxy measures. This may have resulted in misclassification of youth and biased effect estimates. In addition, the number of people who completed the entire survey differed by country of birth and ethnicity. It is possible that youth of low acculturation did not complete the entire questionnaire, thus biasing the results toward no effect. Another limitation was our use of selfreports of height and weight and, therefore, BMI. Previous research has found that youth will overestimate their height and underestimate their weight, although it found no differences by ethnic group. ${ }^{26}$

\section{Conclusion}

Country of birth and ethnicity act as determinants of BMI, individually and synergistically. We investigated the effect of 
Table 1: Mean BMI percentile of grade $6-10$ students by immigration status and additional covariables based on the 2010 Canadian Health Behaviour in School-aged Children study (weighted sample $n=19$ 272)*

\begin{tabular}{|c|c|c|c|c|}
\hline \multirow[b]{2}{*}{ Characteristics of the study population } & \multirow[b]{2}{*}{$\begin{array}{c}\text { Weighted } \\
\text { sample, no. (\%) }\end{array}$} & \multicolumn{2}{|c|}{ BMI percentile } & \multirow{2}{*}{$\begin{array}{l}\text { Significance } \\
\text { of } \\
\text { difference, } \\
\quad p \dagger\end{array}$} \\
\hline & & Mean $(95 \% \mathrm{Cl})$ & $\begin{array}{l}\text { Difference from } \\
\text { reference group } \\
\quad(95 \% \mathrm{Cl})\end{array}$ & \\
\hline \multicolumn{5}{|l|}{ Country of birth } \\
\hline Canadian born & $17659(91.6)$ & 58 (57 to 58$)$ & Reference & \\
\hline Foreign born & $1613 \quad(8.4)$ & 54 (52 to 55) & $-4(-6$ to -2$)$ & $<0.001$ \\
\hline \multicolumn{5}{|l|}{ Time since immigration, yr } \\
\hline Canadian born & $17659(91.6)$ & 58 (57 to 58$)$ & Reference & \\
\hline$\geq 6$ & $891 \quad(4.6)$ & 52 (50 to 54$)$ & $-6(-8$ to -4$)$ & $<0.001$ \\
\hline $3-5$ & $396 \quad(2.1)$ & 56 (53 to 59$)$ & $-2(-5$ to 1$)$ & 0.30 \\
\hline $1-2$ & $325 \quad(1.7)$ & 55 (52 to 59$)$ & $-2(-6$ to 1$)$ & 0.23 \\
\hline \multicolumn{5}{|l|}{ Ethnicity } \\
\hline Canadian host culture & $15071(78.2)$ & 57 (57 to 58$)$ & Reference & \\
\hline Arab and West Asian & $300 \quad(1.6)$ & $58(54$ to 61$)$ & $1(-3$ to 4$)$ & 0.78 \\
\hline African & $737 \quad(3.8)$ & 60 (58 to 62$)$ & $3(0$ to 5$)$ & 0.028 \\
\hline East Indian and South Asian & $559 \quad(2.9)$ & 52 (49 to 55$)$ & $-5(-8$ to -3$)$ & $<0.001$ \\
\hline East and Southeast Asian & $1089 \quad(5.7)$ & 53 (51 to 56$)$ & $-4(-6$ to -2$)$ & $<0.001$ \\
\hline Latin American & $187 \quad(1.0)$ & 60 (56 to 65$)$ & $3(-2$ to 7$)$ & 0.24 \\
\hline Otherł & $1330 \quad(6.9)$ & 59 (57 to 60$)$ & $1(0$ to 3$)$ & 0.15 \\
\hline \multicolumn{5}{|l|}{ Individual-level covariables } \\
\hline \multicolumn{5}{|l|}{ Sex } \\
\hline Male & $9567(49.6)$ & 61 (60 to 62) & Reference & \\
\hline Female & $9705(50.4)$ & 53 (52 to 54$)$ & $-8(-9$ to -7$)$ & $<0.001$ \\
\hline \multicolumn{5}{|l|}{ Perceived family wealth } \\
\hline Well off & $11064(57.4)$ & 56 (55 to 57 ) & Reference & \\
\hline Average & $6436(33.4)$ & 58 (57 to 59$)$ & 2 (1 to 3 ) & $<0.001$ \\
\hline Worse off & $1772 \quad(9.2)$ & 61 (59 to 63$)$ & 5 (3 to 6$)$ & $<0.001$ \\
\hline \multicolumn{5}{|l|}{ Area-level covariables } \\
\hline \multicolumn{5}{|l|}{ Median annual household income, \$ } \\
\hline Quartile 4: > 67605 & $4512(23.4)$ & 56 (55 to 58$)$ & Reference & \\
\hline Quartile 3: 53 115-67 605 & $4440(23.0)$ & 56 (54 to 58$)$ & $0(-2$ to 2$)$ & 0.85 \\
\hline Quartile 2: $\quad 43571-53114$ & $4311(22.4)$ & 56 (55 to 58 ) & $0(-2$ to 2$)$ & 0.99 \\
\hline Quartile 1: < 43571 & $6008(31.2)$ & 59 (58 to 61$)$ & 3 (1 to 5$)$ & 0.002 \\
\hline \multicolumn{5}{|l|}{ Immigrants in the community, $\%$} \\
\hline Quartile 4: $\geq 17$ & $6399(33.2)$ & 55 (54 to 56$)$ & Reference & \\
\hline Quartile 3: $\quad 9$ to $<17$ & $5095(26.4)$ & 58 (57 to 60$)$ & 3 (1 to 5$)$ & $<0.001$ \\
\hline Quartile 2: $\quad 3$ to $<9$ & $4319(22.4)$ & 58 (57 to 60$)$ & $3(1$ to 5$)$ & $<0.001$ \\
\hline Quartile 1: $<3$ & $3459(18.0)$ & 58 (56 to 60$)$ & $3(1$ to 5$)$ & 0.008 \\
\hline \multicolumn{5}{|l|}{$\begin{array}{l}\text { Statistics Canada population centre } \\
\text { category }\end{array}$} \\
\hline Large urban centre & $6275(32.6)$ & 56 (54 to 57 ) & Reference & \\
\hline Medium centre & 3501 (18.2) & 57 (55 to 59 ) & $1(-1$ to 3$)$ & 0.24 \\
\hline Small centre & $8898(46.2)$ & 58 (57 to 59$)$ & $2(0$ to 4$)$ & 0.015 \\
\hline Rural & $597 \quad(3.1)$ & 60 (57 to 64$)$ & 5 (1 to 8$)$ & 0.019 \\
\hline \multicolumn{5}{|c|}{$\begin{array}{l}\text { Note: } \mathrm{Cl}=\text { confidence interval. } \\
\text { * } n \text { values were weighted according to the Canadian Health Behaviour in School-aged Children study protocol. }{ }^{22} \text { Totals in a category may vary } \\
\text { slightly due to rounding. } \\
\text { tWe compared the levels of the variables for significant differences while controlling for the clustering effect of school. } \\
\text { tThe "other" ethnic group includes youth who identified with more than } 1 \text { of the } 6 \text { ethnic groups. }\end{array}$} \\
\hline
\end{tabular}




\section{OPEN}

Research

Table 2: Mean BMI percentiles of Canadian youth predicted by three proposed models by country of birth and ethnicity*

\begin{tabular}{|c|c|c|c|c|c|c|}
\hline \multirow[b]{2}{*}{ Main effects } & \multicolumn{2}{|c|}{ Base model } & \multicolumn{2}{|c|}{ Adjusted model } & \multicolumn{2}{|c|}{$\begin{array}{c}\text { Adjusted with explanatory } \\
\text { variables }\end{array}$} \\
\hline & $\begin{array}{l}\text { BMI percentile, } \\
\text { mean }(95 \% \mathrm{CI})\end{array}$ & $\begin{array}{c}\text { Difference } \\
\text { from reference, } \\
p\end{array}$ & $\begin{array}{l}\text { BMI percentile, } \\
\text { mean }(95 \% \mathrm{Cl})\end{array}$ & $\begin{array}{c}\text { Difference } \\
\text { from reference, } \\
p\end{array}$ & $\begin{array}{l}\text { BMI percentile, } \\
\text { mean }(95 \% \mathrm{Cl})\end{array}$ & $\begin{array}{c}\text { Difference } \\
\text { from reference, } \\
p\end{array}$ \\
\hline \multicolumn{7}{|l|}{ Country of birth } \\
\hline \multicolumn{7}{|l|}{ Ethnicity } \\
\hline Canadian host culture & $56(55-57)$ & Reference & $57(56-59)$ & Reference & $57(56-59)$ & Reference \\
\hline Arab and West Asian & $57(54-61)$ & 0.36 & $59(56-63)$ & 0.29 & $59(55-63)$ & 0.46 \\
\hline African & $59(57-61)$ & 0.01 & $60(58-63)$ & 0.007 & $59(56-62)$ & 0.12 \\
\hline $\begin{array}{l}\text { East Indian and South } \\
\text { Asian }\end{array}$ & $51(49-54)$ & 0.003 & $54(51-57)$ & 0.016 & $53(50-56)$ & 0.005 \\
\hline Latin American & $60(55-64)$ & 0.076 & $62(57-66)$ & 0.066 & $61(56-66)$ & 0.14 \\
\hline Other & $57(55-59)$ & 0.097 & $59(57-61)$ & 0.077 & $57(55-59)$ & 0.91 \\
\hline \multicolumn{7}{|c|}{$\begin{array}{l}\text { Note: } \mathrm{Cl}=\text { confidence interval. } \\
\text { 'The base model did not control for any covariables. The adjusted model controlled for gender, age, individual-level perceived family wealth, median neighbourhood } \\
\text { income, percentage of immigrants in the community and Statistics Canada's population centre category. The adjusted model with explanatory variables controlled for all } \\
\text { variables in the adjusted model, plus television watching, computer use, playing video games, physical activity, snacking while watching television, snacking while on the } \\
\text { computer or playing video games and frequency of eating at fast-food restaurants. }\end{array}$} \\
\hline
\end{tabular}

Table 3: Interaction between ethnicity and country of birth among Canadian youth, controlling for level of physical activity and eating behaviours*

\begin{tabular}{|c|c|c|c|c|c|}
\hline \multirow[b]{2}{*}{ Ethnicity } & \multirow[b]{2}{*}{ Country of birth } & \multirow[b]{2}{*}{$n$} & \multirow{2}{*}{$\begin{array}{l}\text { BMI percentile, } \\
\text { mean }(95 \% \mathrm{Cl})\end{array}$} & \multicolumn{2}{|c|}{$\begin{array}{l}\text { Difference between Canadian- } \\
\text { and foreign-born youth }\end{array}$} \\
\hline & & & & Mean $(95 \% \mathrm{Cl})$ & $p$ value \\
\hline \multirow{2}{*}{$\begin{array}{l}\text { Canadian host } \\
\text { culture }\end{array}$} & Canadian born & 14650 & 59 (58 to 60$)$ & Reference & \\
\hline & Foreign born & 421 & 53 (49 to 56 ) & $-6(-9$ to -3$)$ & $<0.001$ \\
\hline \multirow{2}{*}{$\begin{array}{l}\text { Arab and West } \\
\text { Asian }\end{array}$} & Canadian born & 182 & 65 (60 to 70$)$ & Reference & \\
\hline & Foreign born & 118 & 50 (45 to 56$)$ & $-14(-22$ to -7$)$ & $<0.001$ \\
\hline \multirow[t]{2}{*}{ African } & Canadian born & 569 & 60 (57 to 63 ) & Reference & \\
\hline & Foreign born & 168 & 60 (54 to 65) & $-1(-6$ to 5$)$ & 0.84 \\
\hline \multirow{2}{*}{$\begin{array}{l}\text { East Indian and } \\
\text { South Asian }\end{array}$} & Canadian born & 344 & 56 (53 to 60) & Reference & \\
\hline & Foreign born & 214 & 48 (44 to 53$)$ & $-8(-14$ to -3$)$ & 0.003 \\
\hline \multirow{2}{*}{$\begin{array}{l}\text { East and } \\
\text { Southeast Asian }\end{array}$} & Canadian born & 615 & 53 (50 to 56$)$ & Reference & \\
\hline & Foreign born & 475 & 55 (52 to 59) & $3(-1$ to 7$)$ & 0.16 \\
\hline \multirow[t]{2}{*}{ Latin American } & Canadian born & 102 & 61 (54 to 68) & Reference & \\
\hline & Foreign born & 85 & 61 (54 to 68 ) & $0(-9$ to 10$)$ & 0.96 \\
\hline \multirow[t]{2}{*}{ Other } & Canadian born & 1206 & 59 (57 to 61$)$ & Reference & \\
\hline & Foreign born & 124 & 58 (52 to 64$)$ & $-1(-7$ to 5$)$ & 0.72 \\
\hline \multicolumn{6}{|c|}{$\begin{array}{l}\text { Note: } \mathrm{Cl}=\text { confidence interval. } \\
{ }^{*} \text { The model controlled for gender, age, individual level perceived family wealth, median neighbourhood income, percentage of } \\
\text { immigrants in the community and Statistics Canada population centre category, as well as television watching, computer use, } \\
\text { playing video games, physical activity, snacking while watching television, snacking while on the computer or playing video games } \\
\text { and frequency of eating at fast-food restaurants. }\end{array}$} \\
\hline
\end{tabular}


important health behaviours on these differences and found that they did not explain observed differences. For those in public health, our findings stress the importance of considering both ethnicity and country of birth when designing and implementing weight-loss interventions. Given the high proportion of Canadians who are immigrants, uncovering reasons for weight gain will lead to a better understanding of the determinants of childhood BMI.

\section{References}

1. Berry JW. A psychology of immigration. 7 Soc Issues 2001;57:615-31.

2. Désilets MC, Rivard M, Shatenstein B, et al. Dietary transition stages based on eating patterns and diet quality among Haitians of Montreal, Canada. Public Health Nutr 2007;10:454-63.

3. Roshania R, Narayan KM, Oza-Frank R. Age at arrival and risk of obesity among US immigrants. Obesity (Silver Spring) 2008;16:2669-75.

4. Hauck K, Hollingsworth B, Morgan L. BMI differences in 1st and 2nd generation immigrants of Asian and European origin to Australia. Health Place 2011;17:78-85.

5. Adekunle B, Filson G, Sethuratnam S, et al. Acculturation and consumption: examining the consumption behavior of people of Afro-Caribbean descent in Canada. Fournal of Agriculture, Food Systems, and Community Development 2011;2:297-313.

6. Roberts KC, Shields M, de Groh M, et al. Overweight and obesity in children and adolescents: results from the 2009 to 2011 Canadian Health Measures Survey. Health Rep 2012;23:37-41

7. Cole TJ, Bellizzi MC, Flegal KM, et al. Establishing a standard definition for child overweight and obesity worldwide: international survey. BMF 2000;320: 1240-3.

8. Han JC, Lawlor DA, Kimm SYS. Childhood obesity. Lancet 2010;375:1737-48

9. Harriger JA, Thompson JK. Psychological consequences of obesity: weight bias and body image in overweight and obese youth. Int Rev Psychiatry 2012; 24:247-53.

10. Quon EC, McGrath JJ, Roy-Gagnon MH. Generation of immigration and body mass index in Canadian youth. 7 Pediatr Psychol 2012;37:843-53.

11. Maximova K, O'Loughlin J, Gray-Donald K. Healthy weight advantage lost in one generation among immigrant elementary schoolchildren in multi-ethnic, disadvantaged, inner-city neighborhoods in Montreal, Canada. Ann Epidemiol 2011;21:238-44.

12. O'Loughlin J, Paradis G, Renaud L, et al. Prevalence and correlates of overweight among elementary schoolchildren in multiethnic, low income, innercity neighbourhoods in Montreal, Canada. Ann Epidemiol 1998;8:422-32.

13. Singh GK, Kogan MD, Yu SM. Disparities in obesity and overweight prevalence among US immigrant children and adolescents by generational status. 7 Community Health 2009;34:271-81.

14. Au L, Kwong K, Chou JC, et al. Prevalence of overweight and obesity in Chinese American children in New York City. 7 Immigr Minor Health 2009;11:337-41.

15. Kirchengast $S$, Schober E. To be an immigrant: a risk factor for developing overweight and obesity during childhood and adolescence? 7 Biosoc Sci 2006; 38:695-705.

16. Taverno SE, Rollins BY, Francis LA. Generation, language, body mass index, and activity patterns in Hispanic children. Am 7 Prev Med 2010;38:145-53.

17. Strickman-Stein N, Gervais M, Ludwig DA, et al. Body mass index as a function of length of United States residency among Haitian immigrant children. Ethn Dis 2010;20:22-8.

18. Harris KM, Perreira KM, Lee D. Obesity in the transition to adulthood: predictions across race/ethnicity, immigrant generation, and sex. Arch Pediatr Adolesc Med 2009; 163:1022-8.

19. Tzotzas T, Kapantais E, Tziomalos K, et al. Epidemiological survey for the prevalence of overweight and abdominal obesity in Greek adolescents. Obesity (Silver Spring) 2008;16:1718-22.

20. Renzaho AM, Gibbons C, Swinburn B, et al. Obesity and undernutrition in sub-Saharan African immigrant and refugee children in Victoria, Australia. Asia Pac 7 Clin Nutr 2006;15:482-90.

21. Van Hook J, Balistreri KS. Immigrant generation, socioeconomic status, and economic development of countries of origin: a longitudinal study of body mass index among children. Soc Sci Med 2007;65:976-89.

22. Freeman JG, King M, Pickett W, et al. The bealth of Canada's young people: a mental health focus. Ottawa: Public Health Agency of Canada; 2011.

23. 2006 census of population. Ottawa: Statistics Canada; 2006. Available: www12.statcan.gc.ca/census-recensement/2006/index-eng.cfm (accessed 2013 Dec. 5).

24. Simpson K, Janssen I, Craig WM, et al. Multilevel analysis of associations between socioeconomic status and injury among Canadian adolescents. 7 Epidemiol Community Health 2005;59:1072-7.

25. Tri-council policy statement: ethical conduct for research involving humans. Ottawa: Canadian Institutes of Health Research, Natural Sciences and Engineering
Research Council of Canada and Social Sciences and Humanities Research Council of Canada; 2010. Cat no MR21-18/2010E-PDF.

26. Brener ND, Mcmanus T, Galuska D, et al. Reliability and validity of selfreported height and weight among high school students. 7 Adolesc Health 2003;32:281-7.

27. de Onis M, Onyango AW, Borghi E, et al. Development of a WHO growth reference for school-aged children and adolescents. Bull World Health Organ 2007;85:660-7. Available: www.who.int/growthref/growthref_who_bull/en/index .html (accessed 2013 Dec. 5).

28. Balistreri KS, Van Hook J. Trajectories of overweight among US school children: a focus on social and economic characteristics. Matern Child Health 7 2011;15:610-9.

29. Van Hook J, Baker E. Big boys and little girls: gender, acculturation, and weight among young children of immigrants. 7 Health Soc Behav 2010;51:200-14.

30. Gordon-Larsen P, Harris KM, Ward DS, et al. Acculturation and overweightrelated behaviors among Hispanic immigrants to the US: the National Longitudinal Study of Adolescent Health. Soc Sci Med 2003;57:2023-34.

31. Schnohr CW, Kreiner S, Due EP, et al. Differential item functioning of a family affluence scale: validation study on data from HBSC 2001/02. Soc Indic Res 2008;89:79-95.

32. Liu J, Probst JC, Harun N, et al. Acculturation, physical activity, and obesity among Hispanic adolescents. Ethn Health 2009;14:509-25.

33. From urban areas to population centres. Ottawa (ON): Statistics Canada; 2011. Available: www.statcan.gc.ca/subjects-sujets/standard-norme/sgc-cgt/noticeavis/sgc-cot-06-eng.htm (accessed 2013 Dec. 5)

34. Monasta L, Batty GD, Cattaneo A, et al. Early-life determinants of overweight and obesity: a review of systematic reviews. Obes Rev 2010;11:695-708.

35. Steinbeck KS. The importance of physical activity in the prevention of overweight and obesity in childhood: a review and an opinion. Obes Rev 2001;2:117-30.

36. Schmitz KH, Harnack L, Fulton JE, et al. Reliability and validity of a brief questionnaire to assess television viewing and computer use by middle school children. 7 Sch Health 2004;74:370-7.

37. Prochaska JJ, Sallis JF, Long B. A physical activity screening measure for use with adolescents in primary care. Arch Pediatr Adolesc Med 2001;155:554-9.

38. Van den Bulck J, Van Mierlo J. Energy intake associated with television viewing in adolescents, a cross sectional study. Appetite 2004;43:181-4.

39. Griebler R, Molcho M, Samdal O, et al. Health Behaviour in School-Aged Children: a World Health Organization cross national study, research protocol for the 2009/2010 survey. Vienna: Ludwig Boltzmann Institut Health Promotion Research, and Edinburgh: Child and Adolescent Health Research Unit; 2010.

40. Merlo J, Yang M, Chaix B, et al. A brief conceptual tutorial on multilevel analysis in social epidemiology: investigating contextual phenomena in different groups of people. 7 Epidemiol Community Health 2005;59:729-36.

41. Kahlin Y, Werner S, Romild U, et al. Self-related health, physical activity, BM and musculoskeletal complaints: a comparison between foreign and Swedish high school students. Int f Adolesc Med Health 2009;21:327-41.

42. Tremblay MS, Pérez CE, Ardern CI, et al. Obesity, overweight and ethnicity. Health Rep 2005;16:23-34.

43. Keith SW, Redden DT, Katzmarzyk PT, et al. Putative contributors to the secular increase in obesity: exploring the roads less traveled. Int 7 Obes (Lond) 2006; 30:1585-94.

44. Unger JB, Reynolds K, Shakib S, et al. Acculturation, physical activity, and fastfood consumption among Asian-American and Hispanic adolescents. 7 Community Health 2004;29:467-81.

Affiliations: Department of Public Health Sciences (Kukaswadia, Pickett, Janssen), Queen's University; Clinical Research Centre (Pickett), Kingston General Hospital; School of Kinesiology and Health Studies (Janssen), Queen's University, Kingston, Ont.

Contributors: All authors conceived the study design. Atif Kukaswadia conducted the statistical analyses, had full access to all of the data in the study and takes responsibility for the integrity of the data and the accuracy of the data analysis. All authors interpreted the findings, were involved in writing the paper and gave final approval of the submitted and published versions. All authors agreed to act as guarantors of this work.

Competing interests: Atif Kukaswadia has received personal fees from the Canadian Obesity Network unrelated to this study. Ian Janssen has received speaker honoraria from Public Health Ontario; consulting fees from Health Canada, the Public Health Agency of Canada and Active Healthy Kids Canada; conference travel support from Public Health Ontario, Active Healthy Kids Canada, the Heart and Stroke Foundation of Ontario, the International Development Research Centre, the Canadian Society of Exercise Physiology, the American College of Sports Medicine, the Canadian Obesity Network, the University of Guadalajara and Food \& Consumer Products of Canada; funding for graduate students from the Ontario Ministry of Research and Innovation; and an operating grant from the International Development Research Centre. 
Funding: The Canadian Health Behaviour in School-Aged Children study (principal investigators John Freeman and William Pickett) was funded by the Public Health Agency of Canada and Health Canada. This analysis was supported by the Canadian Institutes of Health Research and the Heart and Stroke Foundation of Canada (MOP 97961; PCR 101415). Atif Kukaswadia was supported by a Canadian Institutes of Health Research Frederick Banting and Charles Best Canada Graduate Scholarships Doctoral Award. Ian Janssen was supported by a tier 2 Canada Research Chair in Physical Activity and Obesity. The funders did not have any role in the design or conduct of the study; collection, management, analysis or interpretation of the data; preparation, review or approval of the manuscript; or decision to submit the manuscript for publication.
Acknowledgements: Health Behaviour in School-Aged Children is a World Health Organization/Euro collaborative study. The international coordinator of the 2009-2010 study is Candace Currie, St. Andrews University, Scotland; the databank manager is Oddrun Samdal, University of Bergen, Norway. We thank Andrei Rosu for the collection of geographic information integral to this analysis and for feedback and support regarding the geographic variables; we thank Andrew Day for statistical support and feedback.

Supplemental information: For reviewer comments and the original submission of this manuscript, please see www.cmajopen.ca/content/2 /3/E145/suppl/DC1 